\title{
Lasertripsy For the Controlled Coarse Fragmentation of Urinary Tract Stones
}

\author{
OL Antipov ${ }^{1 *}$, OS Streltsova ${ }^{2}$, DP Pochtin ${ }^{3}$, ID Eranov ${ }^{4}$ and EV Grebenkin ${ }^{2}$ \\ ${ }^{1}$ Institute of Applied Physics of the Russian Academy of Sciences (IAPRAS), Nizhny Novgorod, Russia \\ ${ }^{2}$ Privolzhsky Research Medical University, Nizhny Novgorod, Russia
}

${ }^{3}$ NA Semashko Nizhny Novgorod Regional Clinical Hospital, Nizhny Novgorod, Russia

${ }^{4}$ NI Lobachevsky State University of Nizhny Novgorod, Nizhny Novgorod, Russia

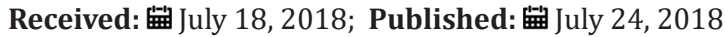

*Corresponding author: Oleg L Antipov, Institute of Applied Physics of the Russian Academy of Sciences (IAPRAS), 46 Ulyanova st, Nizhny Novgorod 603155, Russia

\begin{abstract}
Development of novel methods for controlled coarse fragmentation of urinary tract stones may help to minimise the risk of urinary tract infection and prevent the small stone fragments, responsible for residual stone formation, from entering into the calyxcalcification system of a kidney. The experimental results demonstrated that the following parameters of a pulsed laser operating at the $2097 \mathrm{~nm}$ (or the $1967 \mathrm{~nm}$ ) wavelength were optimal for a controlled fractioning of the stones in air: the pulse duration of 20-30 $\mathrm{ns}$, the repetition rate of 200-1000 $\mathrm{Hz}$ (or more), and pulse energy of 45-55 mJ. The relatively small pulse energy coupled with the high repetition rate enabled the destruction of concrements into fragments small enough to be removed with the amplatz.
\end{abstract}

Keywords: Lithotripsy; Urolithiasis; Lasers

\section{Introduction}

Decades of endoscopic surgery of urolithiasis using fine fragmentation of stones have revealed its deficiencies, one of which is the complication of contact laser lithotripsy - the development of an infectious inflammatory process in kidneys due to bacterial dissemination of flora from stone biofilms [1]. Importantly, even in the case of sterile urine, some microorganisms were found in the urinary tract stones in $25 \%$ to $41 \%$ of all cases according to published reports $[2,3]$. The problem of the development of complications in the endoscopic treatment of urolithiasis, coupled with increased antibiotic resistance, is becoming more urgent. The search for new methods for controlled coarse fragmentation of stones will minimize the risk of possible infection and help to prevent the loss of small fragments of stones in the calyxcalcification system of a kidney, which were found to be responsible for residual stone formation.

\section{Purpose}

Search for the regime of laser lithotripsy that will ensure effective fragmentation of the urinary calculi and at the same time avoid their uncontrolled finely fragmented fracture.

\section{Materials and Methods}

The effect of a laser crushing of 25 urinary tract stones ex vivo was studied. The used stones are crushed after nephrolitho extraction and pyelolithotomy, nephrectomy. In the experiment, only undistracted (entirely extracted) stones were examined, which were placed in physiological saline until the moment of the laser action. A Ho3+:YAG laser pumped by a Tm3+ fiber laser was used in the first experiments. The Ho3+:YAG laser operated in a pulsed regime at the $2097 \mathrm{~nm}$ wavelength and the 20-40 ns pulse duration. The Ho3+:YAG pulse repetition rate was varied from 0.2 to $40 \mathrm{kHz}$, while the pulse energy changed within $0.5-55 \mathrm{~mJ}$ at the average output power of up to $35 \mathrm{~W}$. In the second experiments, another pump laser based on Tm3+-doped Lu203 ceramic at 1967 nm wavelength was in turn pumped by a Raman-shifted Er3+ fiber laser at the $1670 \mathrm{~nm}$ wavelength. The pulsed Tm3+:Lu203 laser had a pulse duration of 30-40 ns and the pulse frequency of 14-25 $\mathrm{kHz}$. It operated with the average output power from $100 \mathrm{~mW}$ to 10 W. Both Ho3+:YAG and Tm3+:Lu203 lasers were manufactured at the IAPRAS (Nizhny Novgorod) [4,5]. The efficiency of the laser- 
stone interaction was estimated by measuring the time required for stone perforation. The created stone channel was inspected visually

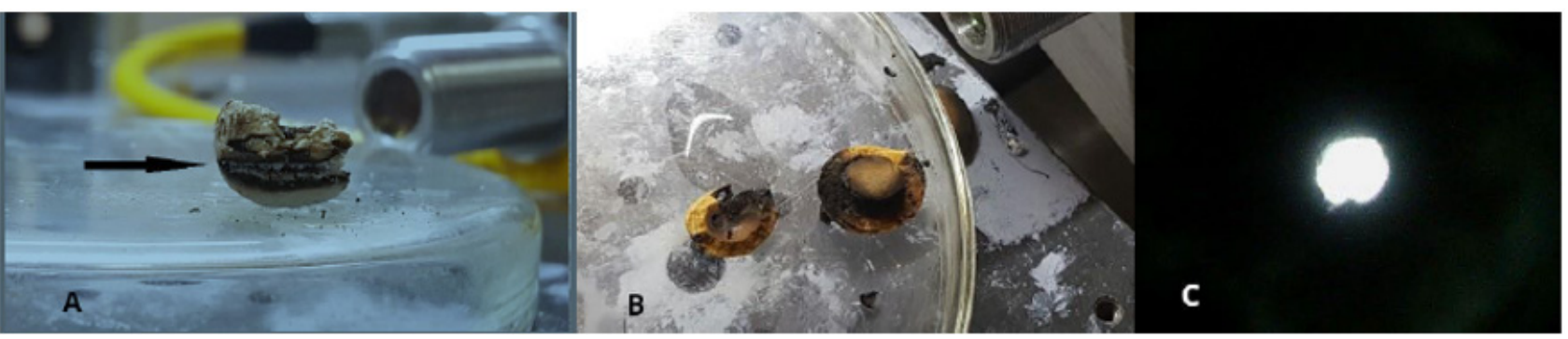

Figure 1: Results of Ho3+:YAG laser irradiation of the urinary tract stones; A - stone fracturing along the fault line (indicated by an arrow); B - fragments of a stone; C - examination of the perforated stones using transmitted light microscopy (10× lens, 10× eyepiece).

\section{Technique of the Experiment}

The stones were removed from the normal saline $0.9 \%$ $\mathrm{NaCl})$ and placed on an optical table. The Ho3+:YAG laser beam (or the $\mathrm{Tm}^{3+}: \mathrm{Lu}_{2} \mathrm{O}_{3}$ laser beam) was focused into the stone using lenses with the effective focal length from $21 \mathrm{~mm}$ to $200 \mathrm{~mm}$ (the estimated laser beam diameter on a stone changed from 0.1 to $1 \mathrm{~mm}$, measured at the e- 2 intensity level). The time required for complete stone perforation or stone fracturing along the fault line was measured. The inspection of the received stone channel was performed visually and by using transmitted light microscopy (Leica DMLS microscope, $10 \times$ lens, $10 \times$ eyepiece).

\section{Results}

The diameter of the stones used in experiments was 8 to 20 $\mathrm{mm}$. Their microstructural density of the stones was from 161 to $1933 \mathrm{HU}$. The perforation time was measured from 2 to 300 seconds depending on the stone density, spatial dimensions, and chemical composition. The success rate of stone fracturing using the Ho3+:YAG laser at $2097 \mathrm{~nm}$ with the $10 \mathrm{kHz}$ and $30 \mathrm{kHz}$ pulse repetition rate and 0.17-2.3 mJ pulse energy was 89\% (8 out of 9 attempts were successful). The microstructural density of these stones was from $161 \mathrm{HU}$ up to $1566 \mathrm{HU}$.

The success rate of stone fracturing using the Tm3+:Lu203 laser at $1967 \mathrm{~nm}$ with the $15 \mathrm{kHz}$ frequency and 0.4-0.6 mJ pulse energy was $43 \%$ ( 3 out of 7 attempts were successful). The microstructural density of the stones in this set of experiments was from $401 \mathrm{HU}$ up to $1933 \mathrm{HU}$. A series of experiments revealed that the optimal operation mode of the $2097 \mathrm{~nm} \mathrm{Ho3+:YAG} \mathrm{laser} \mathrm{for} \mathrm{controlled}$ fracturing of urinary tract stones (in air) was a pulsed regime with the repetition rate of 200 to $1000 \mathrm{~Hz}$ (or more), pulse duration of 20-30 ns, and pulse energy of 45-55 mJ. In other words, the laser regime with a relatively small pulse energy (a few tens of $\mathrm{mJ}$ ), but a high repetition rate (hundreds of hertz - kilohertz), enabled coarse fragmentation of concrements into fragments small enough to be removed with the amplatz.

\section{Conclusions}

Prevention of kidney infections after the nephrolithotrypsy procedure can be ensured by a controlled, laser-enabled coarse fragmentation of urinary tract stones. This method allows to avoid scattering of the contents of the stones in a renal cavity system by selecting the laser regime optimal for contact lithotripsy. In the case of a pulsed Ho3+:YAG laser operated at the $2097 \mathrm{~nm}$ wavelength with the pulse energy of 2-55 mJ, pulse duration of 20-40 ns, and pulse repetition rate of $0.2-1 \mathrm{kHz}$ (or more), the urinary tract stones were efficiently fragmented into pieces small enough to be removed from the kidney by percutaneous puncture nephrolithoextraction which, in turn, allowed to prevent infectious and inflammatory processes in kidneys due to minimal microbial dissemination of tissues.

Acknowledgments: This work was supported in part by the Russian Foundation for Basic Research (grant №16-07-00655)."

\section{References}

1. Didenko LV, Perepanova TS, Tolordava ER (2012) K voprosu ob infektsionnom geneze kamney pochek (elektronno-mikroskopicheskoe issledovanie). [Infectious genesis of nephroliths (electron-microscopic study)] Urologiya (3): 4-7

2. Palagin IS, Suhorukova MV, Dehnich AV, Eydelshteyn MV, Shevelev AN, et al. (2012) Sovremennoe sostoyanie antibiotikorezistentnosti vozbuditeley vnebolnichnyih in-fektsiy mochevyih putey $\mathrm{v}$ Rossii: rezultatyi issledovaniya «DARMIS» (2010-2011). [Current State of Antibiotic Resistance of Pathogens Causing Community-Acquired Urinary Tract Infec-tions in Russia: «DARMIS» Study (2010-2011)]. Klinicheskaya mikrobiologiya i antimikrobnaya himioterapiya 14(4): 280-302.

3. Margel D, Ehrlich Y, Brown N, Lask D, Livne P M, et al. (2006) Clinical implication of routine stone culture in percutaneous nephrolithotomy a prospective study. Urology 67(1): 26-29.

4. Antipov OL, Eranov ID, Kositsyin (2017) 36 W Q-switched Ho: YAG laser at $2097 \mathrm{~nm}$ pumped by Tm fiber laser: evaluation of different Ho3+ doping concentrations. Laser Phys Lett 14(1): 015002.

5. Antipov O, Novikov A, Larin S, Obronov I (2016) Highly efficient $2 \mu \mathrm{m}$ $\mathrm{CW}$ and Q-switched $\mathrm{Tm}^{3+}: \mathrm{Lu}_{2} \mathrm{O}_{3}$ ceramics lasers in-band pumped by a Raman-shifted erbium fiber laser at $1670 \mathrm{~nm}$. Optics Letters 41(10): 2298-2301. 
(C) This work is licensed under Creative

To Submit Your Article Click Here:

Submit Article

DOI: 10.32474/JUNS.2018.01.000109

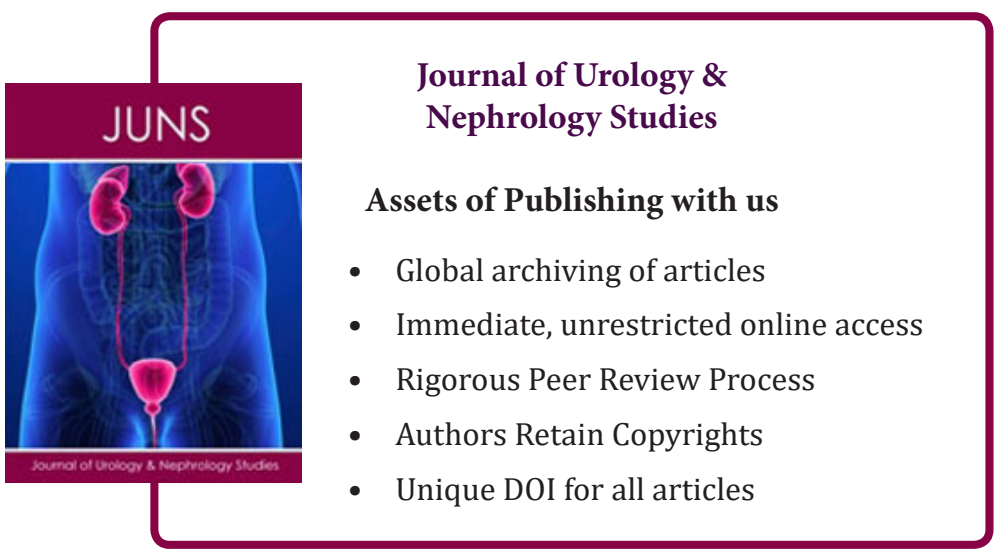

